\title{
Quantitative investigation of the direct interaction between Hemagglutinin and fusion proteins of Peste des petits ruminant virus using surface Plasmon resonance
}

\author{
Xuelian Meng ${ }^{*}$, Ruixue Deng, Xueliang Zhu and Zhidong Zhang
}

\begin{abstract}
Background: The specific and dynamic interaction between the hemagglutinin $(H)$ and fusion $(F)$ proteins of morbilliviruses is a prerequisite for the conformational rearrangements and membrane fusion during infection process. The two heptad repeat regions (HRA and HRB) of $F$ protein are both important for the triggering of F protein.
\end{abstract}

Methods: In this study, the direct interactions of Peste des petits ruminants virus (PPRV) H with F, HRA and HRB were quantitatively evaluated using biosensor surface plasmon resonance (SPR).

Results: The binding affinities of immobilized pCMV-HA-H (HA-H) interacted with proteins pCMV-HA-F (HA-F) and $\mathrm{pCMV}-\mathrm{HA}-\mathrm{HRB}(\mathrm{HA}-\mathrm{HRB})\left(K_{\mathrm{D}}=1.91 \times 10^{-8} \mathrm{M}\right.$ and $2.60 \times 10^{-7} \mathrm{M}$, respectively) reacted an order of magnitude more strongly than that of pCMV-HA-HRA (HA-HRA) and pCMV-HA-Tp IGFR-LD (HA) $\left(K_{D}=1.08 \times 10^{-4} \mathrm{M}\right.$ and 1. $43 \times 10^{-4} \mathrm{M}$, respectively).

Conclusions: The differences of the binding affinities suggested that HRB is involved in functionally important intermolecular interaction in the fusion process.

Keywords: Interactions, Hemagglutinin, Fusion protein, Expression, SPR, Peste des petits ruminanst virus

\section{Background}

Entry processes of enveloped viruses are complex and involve a variety of proteins of virus itself and host. In morbilliviruses, two viral glycoproteins plays the key role in the infection process: the hemagglutinin $(\mathrm{H})$ and fusion $(\mathrm{F})$ proteins [1]. The $\mathrm{H}$ protein is responsible for binding to the target cell, while the $\mathrm{F}$ protein mediates membrane fusion, inducing the virus-cell and cell-cell fusion $[2,3]$. To be fusogenically active, $\mathrm{F}$ protein must be cleaved from the biologically inactive precursor (F0) to two fusogenically active metastable prefusion fragments: a membrane-anchored F1 and a disulfide-linked F2 subunit $[1,4]$. The F1 subunit has several domains: (1) a N-terminus hydrophobic fusion peptide (FP), (2)

\footnotetext{
* Correspondence: mengxuelian@caas.cn

State Key Laboratory of Veterinary Etiological Biology, Lanzhou Veterinary Research Institute, Chinese Academy of Agricultural Sciences, Xujiaping 1, Yanchangpu, Chengguan District, Lanzhou 730046, China
}

two heptad repeat regions (HRA and HRB), (3) a transmembrane (TM) domain, and (4) a C-terminal cytoplasmic tail $[5,6]$. Although the process of $\mathrm{F}$ protein mediated membrane fusion promoted by the $\mathrm{H}$ protein is not precisely known, it is appreciated that fusion is induced through a series of conformational changes of $\mathrm{F}$ protein that has been triggered by specific interaction with the homologous $\mathrm{H}$ protein $[1,7-16]$, and the HRA, $\mathrm{HRB}$ are all important for the triggering of $F$ protein [17-19]. Upon triggering, the heptad repeat regions form a stable six-helix bundle (6-HB), a process intimately linked to membrane fusion [20].

Peste des petits ruminants virus (PPRV), a member of the genus Morbillivirus in the Paramyxoviridae family causes an acutecontagious disease. Recently, major disease events herald an epidemic direction, from west to east [21]. Peste des petits ruminants (PPR) has recently been targeted as the next candidate for global eradication 
following Rinderpest by the World Organization for Animal Health (OIE) and the Food and Agriculture Organization (FAO). Thus, quantifying the binding affinity of $\mathrm{H}$ and HRA, HRB of $F$ protein interaction is of prime importance to better understand their roles in disease induction as well as in developing the therapeutic drugs and control strategies.

Quantifying the binding affinity of protein-protein interactions in vitro is the basis for studying the biochemical processes. To date, various techniques have been used to assess the interaction of protein pairs. Surface plasmon resonance (SPR) is a widely accepted label free biophysical tool in order to investigate biomolecular interactions in real time [22-32]. SPR can accurately provide data on the affinity, specificity, and kinetic constants $\left(k_{\mathrm{a}}\right.$, the association rate parameter; $k_{d}$, the dissociation rate parameter) of biomolecular interactions directly obtained from sensorgrams in few minutes $[24,26,33,34]$. Therefore, the technology should become more accessible and its applications more diverse [35-37].

In this study, we aimed to quantitatively assess the binding affinity and kinetic characterization between PPRV $H$ and F, HRA and HRB using biosensor surface plasmon resonance. As these proteins mainly expressed in the form of inclusion body in prokaryotic expression system, so the first stage of our study was purifying the proteins expressed in eukaryotic cells. The purification of the recombinant proteins were carried out by coimmunoprecipitation (Co-IP) kit and anti-HA monoclonal antibody. Finally, we examined the binding affinity and kinetics of the interaction of $\mathrm{H}$ with $\mathrm{F}$, HRA and HRB.

\section{Methods}

\section{Plasmids, cell and reagents}

The recombinant plasmids pET30a-H (GenBank Accession No. X74443), pCAGGS-F (GenBank Accession No. X74443) and vector pCMV-HA were provided by the Lanzhou Veterinary Research Institute of Chinese Academy of Agricultural Sciences and were used to construct eukaryotic expressing plasmids. CHO-K1 cells were obtained from Shanghai Institutes for Biological Sciences (SIBS). E. coli DH5 $\alpha$, T4 DNA ligase and all restriction enzymes were purchased from TaKaRa. The QIAprep ${ }^{\circ}$ spin miniprep kit was from QIAGENE. F12 K, G418, OPTI-MEM medium and Lipofectamine3000 were products of Invitrogen. FCS was purchased from Gibco BRL Life Tech. Co-IP kit was purchased from Thermo Fisher. Mouse antiHA monoclonal antibody, isotype control antibody, lexa Fluor 488/HRP-conjugated anti-mouse IgG and 3,30-diaminobenzidine tetrahydrochloride (DAB) were purchased from Sigma. Immobilon-P transfer membranes were purchased from Millipore. CM5 sensor chip, amine coupling kit and all solutions were also purchased from GE Healthcare.

\section{Construction of eukaryotic expression vectors}

The gene encoding $\mathrm{H}$ was amplified from pET30a- $\mathrm{H}$ and subcloned into pCMV-HA between $S f i$ I and Kpn I sites to produce the plasmid pCMV-HA-H (HA-H). The gene encoding $\mathrm{F}, \mathrm{HRA}$ and $\mathrm{HRB}$ were amplified from pCAGGS-F and subcloned into pCMV-HA between $B g l$ II and Not I to produce the plasmid pCMV-HA-F (HAF), pCMV-HA-HRA (HA-HRA) and pCMV-HA-HRB (HA-HRB). The constructs HA-H, HA-F, HA-HRA and HA-HRB contained the upstream sequences for HA tag. The constructs were verified by restriction analysis and DNA sequencing (TaKaRa, Dalian, China). According to previous study, HA tag barely interferes the structure and bioactivities of recombinant protein.

\section{Cell culture and transfection}

The CHO-K1 cells were cultured in a six-well plate at a density of $1 \times 10^{6}$ cells in F12 K supplemented with 5\% FCS, $100 \mathrm{U} / \mathrm{mL}$ penicillin and $100 \mathrm{U} / \mathrm{mL}$ streptomycin. When the cells were $80 \%$ confluent, medium was removed and cells were washed with phosphate-buffered saline (PBS). Five microliters of Lipofectamine 3000 $(2 \mathrm{mg} / \mathrm{mL})$ and $4 \mu \mathrm{g}$ DNA were mixed in $250 \mathrm{~mL}$ OPTIMEM medium and incubated for $30 \mathrm{~min}$ at room temperature. The mix was then added to the cells and the plate was incubated at $37{ }^{\circ} \mathrm{C}$ with $5 \% \mathrm{CO} 2$ for $4 \mathrm{~h}$. The transfection mix was then removed and $2 \mathrm{~mL}$ of complete DMEM/F12 was added and incubated for $48 \mathrm{~h}$.

Expression and identification of the recombinant proteins At $48 \mathrm{~h}$ post-transfection, cells were washed twice with PBS and divided into two parts. One part was fixed by $4 \%$ paraformaldehyde for $30 \mathrm{~min}$ at room temperature. After washing three times in PBS, cells were permeabilized by incubation with $0.2 \%$ Triton100 in PBS for $10 \mathrm{~min}$ at $4{ }^{\circ} \mathrm{C}$. The cells were blocked with $5 \%$ bovine serum albumin in PBS for $1 \mathrm{~h}$ at $37{ }^{\circ} \mathrm{C}$ after washing three times in PBS. The cells were then incubated with the mouse anti-HA monoclonal antibody (MAb) in PBS for $1 \mathrm{~h}$ at $37{ }^{\circ} \mathrm{C}$, respectively. This was followed by washing three times in PBS, and the cells were then incubated with donkey anti-mouse IgG-Alexa Fluor 488 conjugate at $37{ }^{\circ} \mathrm{C}$ for $1 \mathrm{~h}$. The cells were washed again and then observed under fluorescence microscope (Olympus).

The cells of the other part were trypsinized and fixed, permeabilized, blocked and processed with anti-HA $\mathrm{MAb}$ and anti-mouse IgG-Alexa Fluor 488 conjugate as described above. Cells were washed and resuspended 
gently in $500 \mu \mathrm{L}$ PBS and were analyzed by flow cytometry (FACSAria 11, BD, USA). The transfected cells, which were treated with isotype control primary antibody, served as controls. Approximately 1000 cells were used for each analysis. Data was analyzed by Flowjo software.

\section{Preparation of proteins}

CHO-K1 cells were expanded in F12 K culture medium and transfected with recombinant plasmids. At $48 \mathrm{~h}$ post-transfection, the cells were harvested and washed two times with ice-cold PBS, and then lysed with lysis buffer 30 minnutes on ice. Cell lysate was collected at $4{ }^{\circ} \mathrm{C}$ and centrifuged at $12000 \mathrm{~g}$ for $10 \mathrm{~min}$. The recombinant proteins in cell lysate were purified by Co-IP kit and anti-HA monoclonal antibody. The purity was tested with SDS-PAGE electrophoresis and bromophenol blue dyeing.

\section{SPR study}

All experiments were performed at $25{ }^{\circ} \mathrm{C}$ using a Biacore $^{\mathrm{Th}} 3000$ instrument and CM5 biosensor chips (Uppsala, Sweden). Kinetic analyses were performed using deafualt settings of Biacore 3000 and recommended SOP walkthrough of CM5 sensorchip. A CM5 sensor chip with carboxymethylated dextran covalently attached on the gold surface was first primed three times with HBS-EP running buffer (10 mM HEPES, pH 7.4, $150 \mathrm{mM} \mathrm{NaCl}, 3 \mathrm{mM}$ ethylenediaminetetraacetic acid and $0.005 \%(\mathrm{v} / \mathrm{v})$ of P20 surfactant) at a flow rate of $10 \mathrm{~mL} / \mathrm{min}$. Flow cell 1 (FC1) was used as the reference flow cell, which was unmodified and lacked the ligand. Flow cell 2 (FC2) was used for immobilization of protein.

Optimal $\mathrm{pH}$ value is the decisive factor that determines the immobilization of protein to the CM5 chip surface. Therefore, Immobilization buffer for immobilizing $\mathrm{HA}-\mathrm{H}$ was first selected separately using the $\mathrm{pH}$ scouting procedure, as described in the instrument protocol, using $10 \mathrm{mM}$ sodium acetate buffers $\mathrm{pH} 4.0$, 4.5, 5.0 and 5.5. The protein was solubilized at a final concentration of $20 \mu \mathrm{g} / \mathrm{mL}$. Each of these solutions $(60 \mu \mathrm{L})$ was individually injected into the sensor at a flow rate of $10 \mu \mathrm{L} / \mathrm{min}$. After each sample application was complete, $50 \mathrm{mM} \mathrm{NaOH}$ was used to clean the sample loop in accordance with the manufacturer's instructions. To control the nonspecific interactions, we performed the same experiment with pCMV-HA-Tp IGFR-LD (HA): the extracellular domain of Taenia pisiformis insulin-like growth factor receptor, at the flow cell 2 of the sensor chip. Each step of the immunoassay was injected at a flow rate of $10 \mu \mathrm{L} / \mathrm{min}$.

The protein HA-H diluted in $10 \mathrm{mM}$ sodium acetate at the optimal $\mathrm{pH}$ was covalently coupled to a CM5 chip with a standard amine-immobilization kit. The carboxyl acid functional groups on the sensor chip surface was activated by 1-ethyl-3-(3-dimethylaminopropyl)carbodiimide hydrochloride (EDC, $0.4 \mathrm{M}$ ) and N-hydroxysuccinimide (NHS, $0.1 \mathrm{M})(1: 1, v / \mathrm{v})$ and $20 \mu \mathrm{g} / \mathrm{mL} \mathrm{HA}-\mathrm{H}$ was immobilized on the sensor surface. The remaining NHS ester groups were blocked by $1 \mathrm{M}$ ethanolamine for $10 \mathrm{~min}$.

To investigate the interaction of $\mathrm{HA}-\mathrm{H}$ with $\mathrm{HA}-\mathrm{F}$, HA-HRA and HA-HRB, the experiment was repeated with different concentrations of analytes (12.5, 25, $50,100$ and $200 \mathrm{nM})$. At the end of the dissociation period of each experiment corresponding to one specific concentration of analytes, the sensor chip was regenerated to remove any remaining bound material with a $30 \mathrm{~s}$ pluse of $10 \mathrm{mM}$ glycine- $\mathrm{HCl}(\mathrm{pH} 2.5)$ at $20 \mu \mathrm{L} / \mathrm{min}$ for subsequent usages. The sensorgrams and measurements for interactions of protein-protein were recorded in real time. Responses were measured in RUs as the difference between active and reference channel. For BIAcore instruments, 1 RU corresponds to $1 \mathrm{pg} / \mathrm{mm}^{2}$.

\section{Data analyses}

Association and dissociation rate constants $\left(k_{\mathrm{a}}\right.$ and $\mathrm{k}_{\mathrm{d}}$, respectively) and the equilibrium dissociation constant $\left(\mathrm{K}_{\mathrm{D}}, \mathrm{k}_{\mathrm{d}} / \mathrm{k}_{\mathrm{a}}\right)$ were obtained by fitting of both the association and dissociation phases for HA-F, HA-HRA and HA-HRB to a single-site binding model (1:1 L binding) with mass transfer limitations for determination of the binding kinetics. Data were analyzed with the BIA evaluation software 4.1 (GE Healthcare, Inc., Piscataway, NJ).

\section{Results}

Expression and identification of the recombinant proteins The amplified gene encoding PPRV H, F, HRA and HRB were digested by restriction enzymes, and directional cloned into pCMV-HA plasmid to generate successfully the $\mathrm{HA}$ fusion expression vectors $\mathrm{HA}-\mathrm{H}$, HA-F, HA-HRA and HA-HRB, respectively. To determine whether recombinant plasmids could express the recombinant proteins with HA tag, an immunofluorescence assay, flow cytometric analysis and western blot analysis were performed. As shown in Fig. 1, fluorescence signal was observed in the plasmids-transfected cells. In contrast, no fluorescence signal was observed in the non-transfected cells. The positive proportions and median of fluorescence intensity of plasmids-transfected $\mathrm{CHO}$ cells treated with anti-HA MAb were far higher than that of cells treated with isotype control antibody (Fig. 2). All recombinant proteins with expected molecular weights were expressed in the transformed cells (Fig. 3). The 


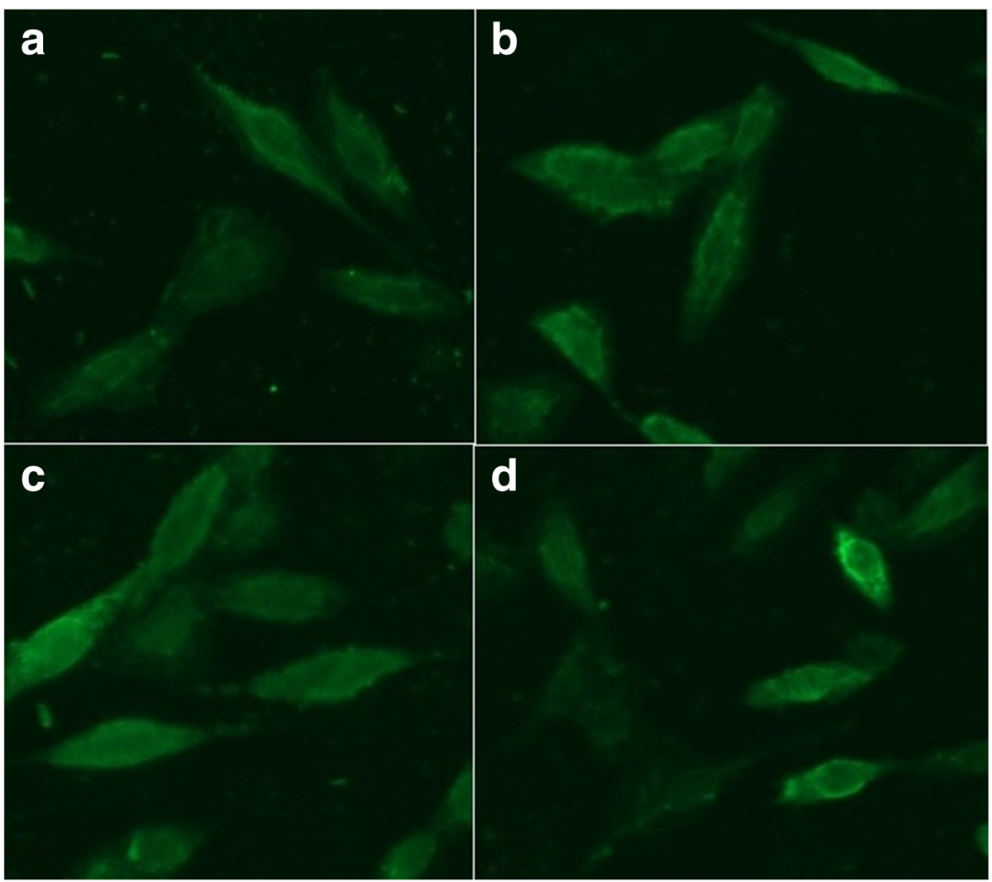

Fig. 1 Indirect immunofluorescent assay of expression of recombinant plasmids. a HA-H transfected cells. b HA-F transfected cells. c HA-HRA transfected cells. $\mathbf{d}$ HA-HRB transfected cells
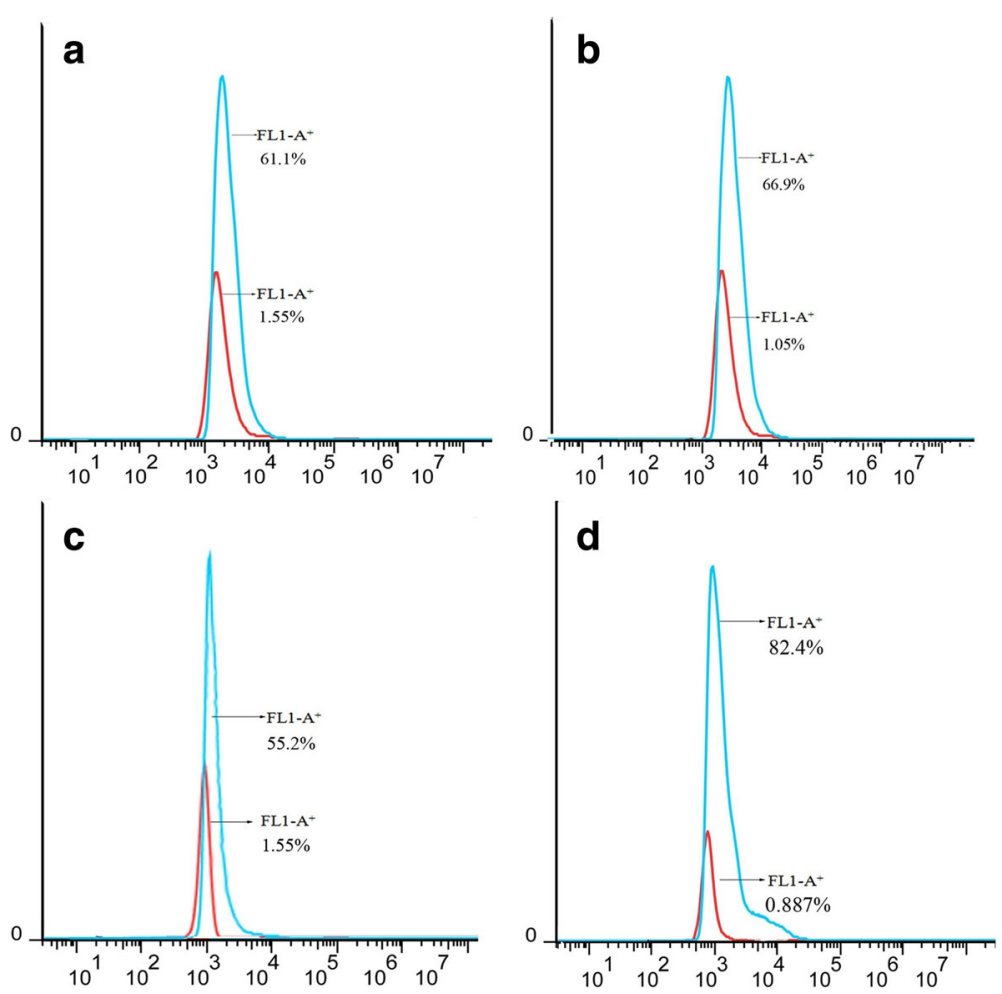

Fig. 2 Flow cytometric analyses of expression of recombinant plasmids. a HA-H transfected cells. $\mathbf{b} H A-F$ transfected cells. $\mathbf{c} H A-H R A$ transfected cells. d HA-HRB transfected cells 


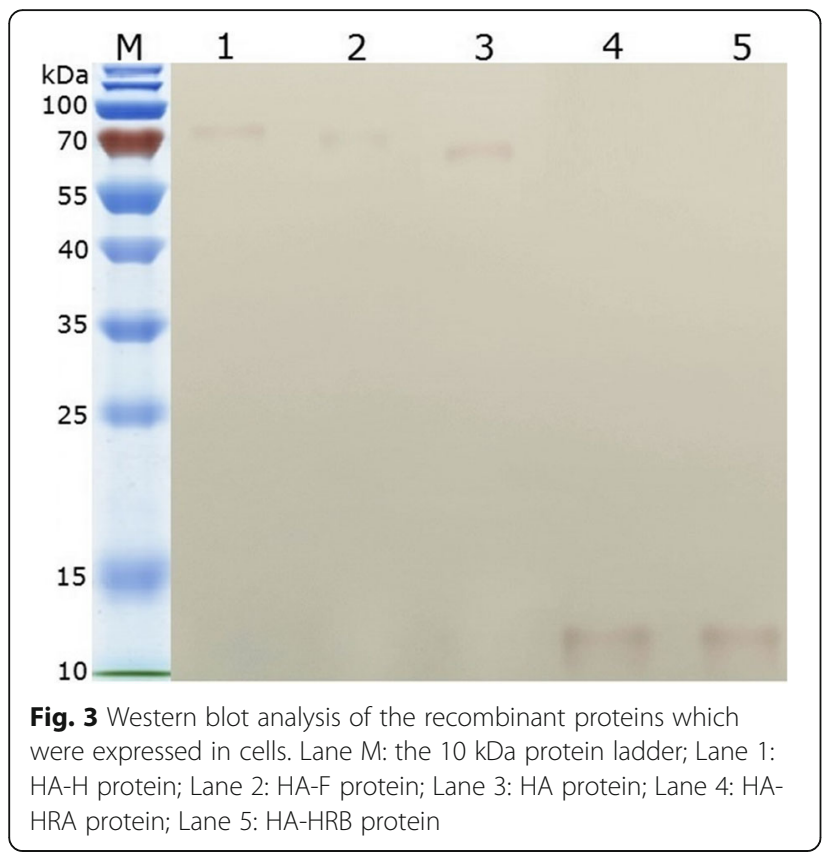

above results confirmed that the recombinant proteins were successfully expressed in cells.

\section{Preparation of the recombinant proteins}

CHO-K1 cells were expanded and transfected with recombinant plasmids HA-H, HA-F, HA-HRA and HA-HRB, respectively. At $48 \mathrm{~h}$ post-transfection, the cells were harvested, washed and lysed. The recombinant proteins were purified by Co-IP kit and antiHA monoclonal antibody. The concentrations of the recombinant proteins HA-H, HA-F, HA-HRA, HAHRB and HA were 233, 331, 243, 315 and $268 \mu \mathrm{g} / \mathrm{mL}$ determined by NanoDrop ND-2000 (Thermo, USA), respectively. The purity of the recombinant proteins were $92.4 \%, 91.7 \%, 93.4 \%, 92.9 \%$ and $92.1 \%$, respectively of HA-H, HA-F, HA-HRA, HA-HRB and HA (Fig. 4).

\section{Preparation of sensor surfaces}

To scout the optimal $\mathrm{pH}$ for immobilization of to the CM5 sensor chip, we tested $10 \mathrm{mM}$ sodium acetate solutions of $\mathrm{pH} 4.0,4.5,5.0$ and 5.5. Of these, the immobilization buffer selected was $10 \mathrm{mM}$ sodium acetate $\mathrm{pH} 4.5$ provided the best electrostatic interaction of HA-H with the chip surface (Fig. 5). We then used EDC and NHS to activate a CM5 chip surface to initiate covalent coupling of $\mathrm{HA}-\mathrm{H}$ diluted in $10 \mathrm{mM}$ sodium acetate $(\mathrm{pH} 4.5)$ to the active surface. Primary amines on the HA-H surface were then cross-linked to esters on the chip surface to form stable amide bonds. Unbound surface-activated

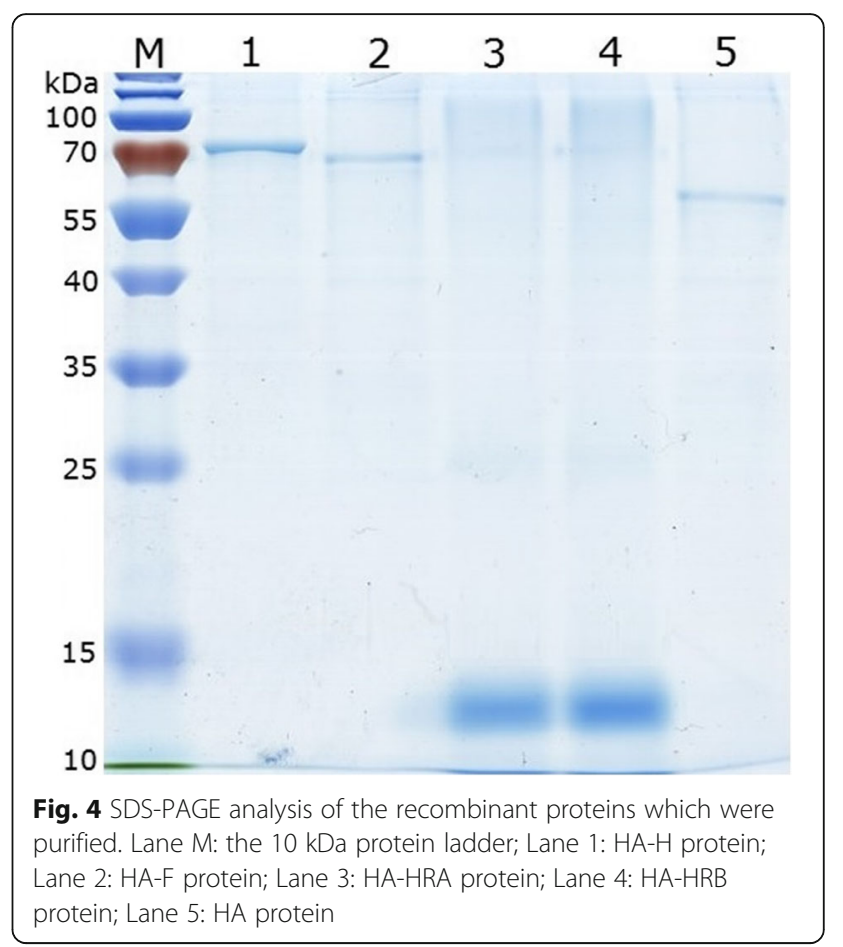

groups were inactivated by $1 \mathrm{M}$ ethanolamine. The expected amount of $6400 \mathrm{RU}$ was detected by Biacore 3000 software.

\section{Capture assay and binding kinetics}

The kinetic study was performed testing different concentrations of purified recombinant proteins against immobilized HA-H. The recombinant proteins were two-fold serially diluted $(12.5,25,50,100$ and $200 \mathrm{nM})$ with

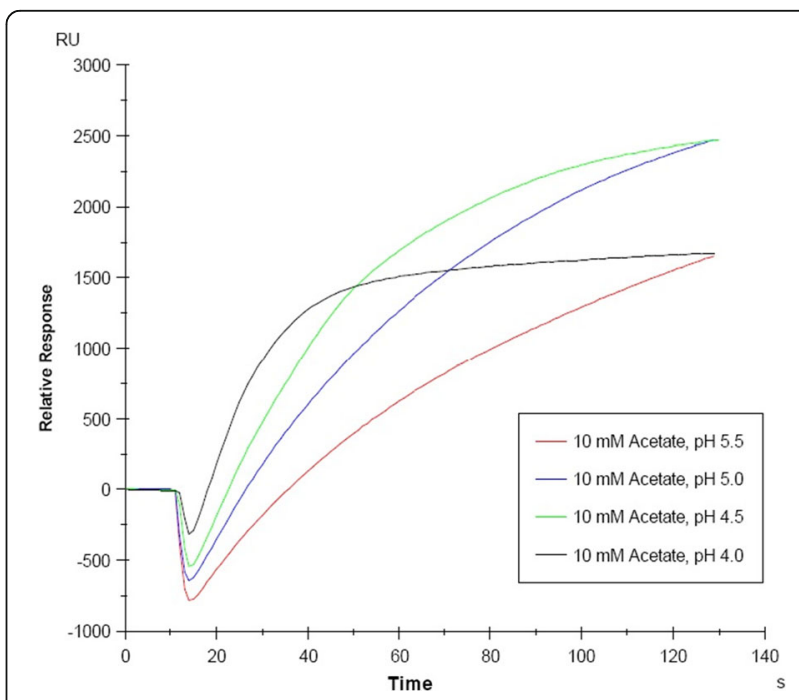

Fig. $5 \mathrm{pH}$ optimization for HA-H immobilization on a CM5 sensor chip. $10 \mathrm{mM}$ sodium acetate solutions of $\mathrm{pH} 4.0,4.5,5.0$, and 5.5 were used, buffer at $\mathrm{pH} 4.5$ was optimal solution for immobilization 
running buffer and then used, involving HA-H immobilized in flow cell 2. Binding results were elaborated independently for each sample. After regeneration, the chip fidelity was sure (Fig. 6a \& 6b). The sensorgrams indicated that $\mathrm{HA}-\mathrm{H}$ interacted strongly with purified recombinant proteins $\mathrm{HA}-\mathrm{F}$ and $\mathrm{HA}-\mathrm{HRB}$, and that the SPR signal increased with increased concentrations of the recombinant proteins (Fig. 6c-f). Little binding was observed HA-H interacted with HA-HRA and HA.

The kinetic parameters $\left(\mathrm{k}_{\mathrm{a}}\right.$ and $\left.\mathrm{k}_{\mathrm{d}}\right)$ and equilibrium dissociation constant $\left(\mathrm{K}_{\mathrm{D}}\right)$ were calculated describing the interactions between each purified protein and the immobilized $\mathrm{H}$ using the 1:1 $\mathrm{L}$ binding model (Table 1). The immobilized $\mathrm{H}$ interacted with proteins HA-F, HA-HRA and HA-HRB with $k_{a}$ values of $4.91 \times 10^{4} \mathrm{M}^{-1} \cdot \mathrm{s}^{-1}>\mathrm{k}_{\mathrm{a}}>3.82 \times 10 \mathrm{M}^{-1} \cdot \mathrm{s}^{-1}, \mathrm{k}_{\mathrm{d}}$ values of $2.99 \times 10^{-3} \mathrm{~s}^{-1}>\mathrm{k}_{\mathrm{d}}>9.37 \times 10^{-4} \mathrm{~s}^{-1}$. The $\mathrm{k}_{\mathrm{a}}$ value of $\mathrm{H}$ interacted with protein $\mathrm{NC}$ was $2.96 \times 10 \mathrm{M}^{-1} \cdot \mathrm{s}^{-1}$, $\mathrm{k}_{\mathrm{d}}$ value of $4.24 \times 10^{-3} \mathrm{~s}^{-1}$. These values indicated a relatively stable complex formed by immobilized $\mathrm{HA}-\mathrm{H}$ and F, HRB. The $K_{D}$ values for binding of HA-F, HA-HRA and HA-HRB to HA-H were $1.91 \times 10^{-8} \mathrm{M}, 1.08 \times 10^{-4} \mathrm{M}$ and $2.6 \times 10^{-7} \mathrm{M}$, respectively. The $\mathrm{K}_{\mathrm{D}}$ value for binding of $\mathrm{HA}$ was $1.43 \times 10^{-4} \mathrm{M}$.

\section{Discussion}

Decisive interactions for viral tropism occur at the viral entry process. H/ Hemagglutinin-neuraminidase $(\mathrm{HN})$ and $\mathrm{F}$ proteins of paramyxovirus are involved in the process. In the past decade, structural biology and biochemistry of $\mathrm{H} / \mathrm{HN}$ and $\mathrm{F}$ proteins of paramyxoviruses have brought new knowledge towards understanding the mechanism of viral membrane fusion. The fusion is induced through a series of conformational changes of $\mathrm{F}$ protein triggered by specific interaction with the homologous $\mathrm{H} / \mathrm{HN}$ protein $[1,9,38]$. In particular, recent studies showed that $\mathrm{H} / \mathrm{HN}$-head, -stalk domains and multiple regions of $\mathrm{F}$ protein, including HRA and $\mathrm{HRB}$, are critical for the interaction of $\mathrm{H} / \mathrm{HN}$ protein with the homologous F protein [17-19, 39-48].

Although the interaction between $\mathrm{H} / \mathrm{HN}$ and $\mathrm{F}$ proteins of paramyxovirus had been investigated by Co-IP, IFA and pull-down in previous studies [11, 12, $14,16,49-51]$, the differences of the interaction force between $\mathrm{H} / \mathrm{HN}$ and $\mathrm{F}$ proteins, especially between $\mathrm{H} /$ $\mathrm{HN}$ and $\mathrm{HRA}, \mathrm{H} / \mathrm{HN}$ and $\mathrm{HRB}$, are still rarely investigated. In order to detect the interaction between proteins by biochemical and biophysical method, it is necessary to prepare soluble proteins. Small affinity

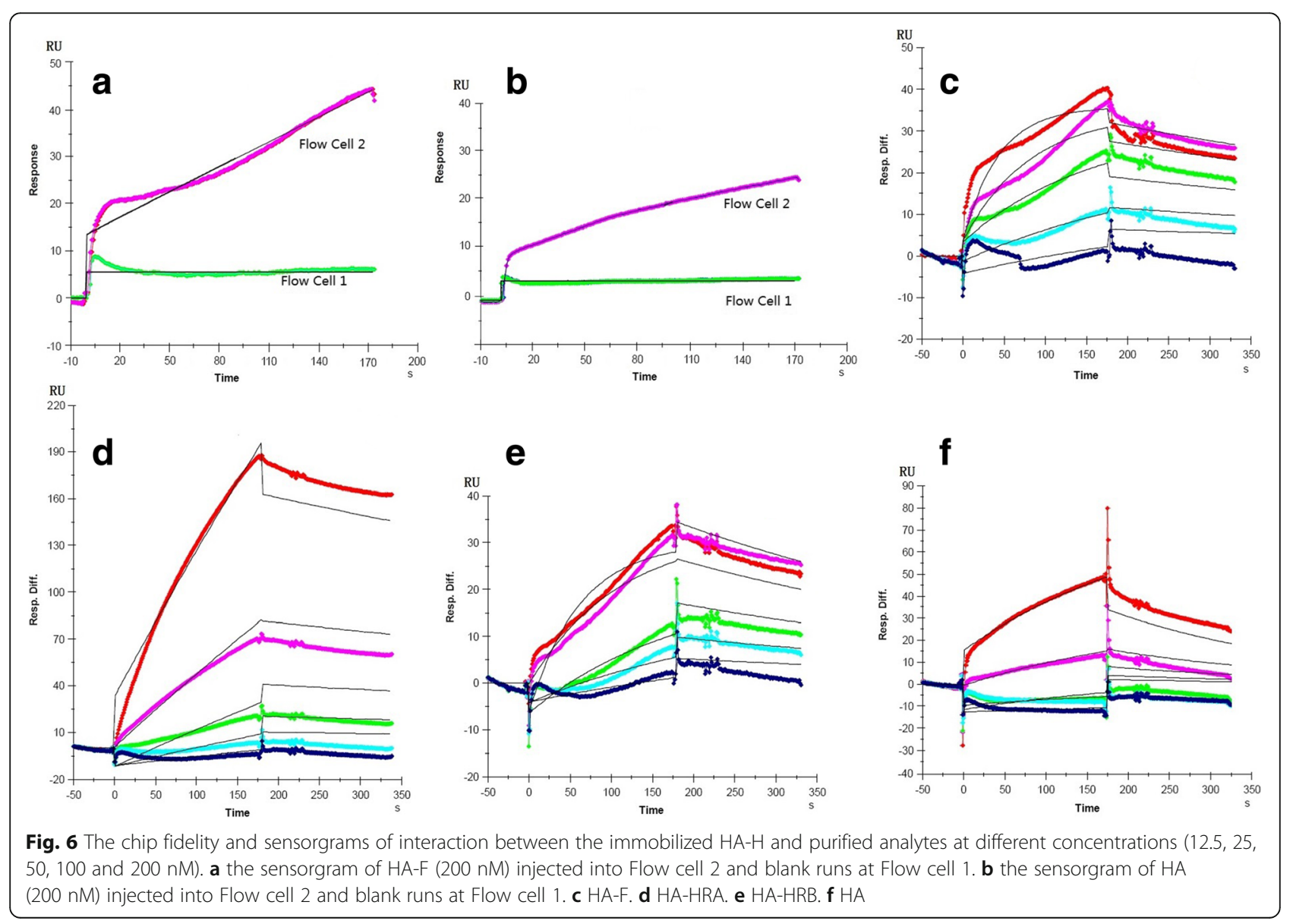


Table 1 The interaction of immobilized HA-H and purified recombinant proteins

\begin{tabular}{llll}
\hline Sample & $k_{a}(1 / \mathrm{Ms})$ & $k_{d}(1 / s)$ & $K D\left(k_{d} / k_{a}, M\right)$ \\
\hline HA-F & $4.91 \times 10^{4}$ & $9.37 \times 10^{-4}$ & $1.91 \times 10^{-8}$ \\
HA-HRA & $3.82 \times 10$ & $4.14 \times 10^{-3}$ & $1.08 \times 10^{-4}$ \\
HA-HRB & $1.15 \times 10^{4}$ & $2.99 \times 10^{-3}$ & $2.60 \times 10^{-7}$ \\
HA & $2.96 \times 10$ & $4.24 \times 10^{-3}$ & $1.43 \times 10^{-4}$ \\
\hline
\end{tabular}

Note: kinetic and affinity data were determined by local fitting of the binding step of the individual sensorgrams to a 1:1 $\mathrm{L}$ binding model. $\mathrm{k}_{\mathrm{a}}$ : association rate constant; $\mathrm{k}_{\mathrm{d}}$ : dissociation rate constant; $\mathrm{K}_{\mathrm{D}}$ : the equilibrium dissociation constant $\left(\mathrm{k}_{\mathrm{d}} / \mathrm{k}_{\mathrm{a}}\right)$

tags offer advantages for expression and purification of the recombinant soluble protein. For the study reported herein, we subcloned the genes encoding PPRV $\mathrm{H}, \mathrm{F}, \mathrm{HRA}$ and HRB into pCMV-HA vectors and obtained successfully high purity of soluble HA$\mathrm{H}, \mathrm{HA}-\mathrm{F}, \mathrm{HA}-\mathrm{HRA}$ and HA-HRB expressed in the CHO-K1 cells by anti-HA tag antibody and Co-IP kit.

We quantitatively evaluated the interactions of HA$\mathrm{H}$ with HA-F, HA-HRA and HA-HRB using SPR. As a surface-sensitive technique, SPR is ideal for studying interactions between immobilized ligands and analytes because it directly generates reliable kinetic constants $\left(\mathrm{k}_{\mathrm{a}}\right.$ and $\mathrm{k}_{\mathrm{d}}$ ) from sensorgrams, and produces the reaction within a few minutes, and can analyze both the association and dissociation phases of an interaction, allowing for the detection of weak binding events that would otherwise be difficult to characterize $[22,52]$. The $R U$ on the surface is directly indicating the amount of analyte bound. A 1:1 "Langmuir binding" model taken into account the limitations of mass transfer was used to fit the data to determine the binding kinetics. The equilibrium dissociation constant $K_{D}$ is calculated by describing the interactions between the immobilized ligands and analytes. Our SPR data demonstrates direct binding of HA-F, HA-HRA and HA-HRB to HA-H. The HA-F and HA-HRB interacted with the immobilized HA-H at an apparent affinity of $2.60 \times 10^{-7} \mathrm{M}>\mathrm{K}_{\mathrm{D}}>1.91 \times$ $10^{-8} \mathrm{M}$, and that of HA-HRB, as well as HA-F protein, was obviously stronger than that of HA-HRA. The data suggested that PPRV HRB plays more important role than HRA in the viral fusion process. The results were consistent with the previous reports using independent means [5, 41]. Unfortunately, due to the non-open source of Biacore3000 and CM5 chip, this restricts the further investigation of the experimental conditions.

\section{Conclusions}

We constructed an efficient system for the purification of HA-H, HA-F, HA-HRA and HA-HRB expressed in CHO-K1. The real-time SPR characterization of the interactions between HA-H and HA-F, HA-HRA, HAHRB was determined for the first time. The data of this study clearly demonstrated the high affinity and specific interactions between the immobilized HA-H and HA-F, HA-HRB by reacted an order of magnitude more strongly than that of HA-HRA and HA. This suggests that HRB is most likely involved in functionally important intermolecular interaction in the fusion process.

\section{Abbreviations \\ Co-IP: Co-immunoprecipitation; DAB: 3: 30-diaminobenzidine tetrahydrochloride; F: Fusion protein; H: Hemagglutinin; HA: pCMV-HA; HA- F: pCMV-HA-F; HA-H: pCMV-HA-H; HA-HRA: pCMV-HA-HRA; HA-HRB: pCMV- HA-HRB; HN: Hemagglutinin-neuraminidase; ka: The association rate parameter; KD (kd/ka): Equilibrium dissociation constant; kd: The dissociation rate parameter; PPR: Peste des petits ruminants; PPRV: Peste des petits ruminants virus; SPR: Surface plasmon resonance \\ Acknowledgements \\ Not applicable. \\ Funding \\ This work was supported in part by the National Natural Science \& Foundation of China (NSFC, 31300142) and National Key Research \& Development Program of China (2016YFD0500108). The contents are solely the responsibility of the authors and do not necessarily represent NSFC or National key research and development program.}

Availability of data and materials

Not applicable.

Authors' contributions

$X L M, R X D$ and XLZ conceived and designed the project and performed the study. XLM wrote manuscript, ZDZ revised the manuscript. All authors read and approved the final manuscript.

Ethics approval and consent to participate

Not applicable.

Consent for publication

Not applicable.

Competing interests

The authors declare that they have no competing interests.

\section{Publisher's Note}

Springer Nature remains neutral with regard to jurisdictional claims in published maps and institutional affiliations.

Received: 12 September 2017 Accepted: 15 January 2018

Published online: 22 January 2018

References

1. Lamb RA, Jardetzky TS. Structural basis of viral invasion: lessons from paramyxovirus F. Curr Opin Struct Biol. 2007;17:427-36.

2. Lamb CA, Dooley HC, Tooze SA. Endocytosis and autophagy: shared machinery for degradation. BioEssays. 2013;35:34-45.

3. Karron RA, Buchholz UJ, Collins PL. Live-attenuated respiratory syncytial virus vaccines. Curr Top Microbiol Immunol. 2013;372:259-84.

4. Chang A, Dutch RE. Paramyxovirus fusion and entry: multiple paths to a common end. Viruses. 2012;4:613-36.

5. Rahaman A, Srinivasan N, Shamala N, Shaila MS. The fusion core complex of the peste des petits ruminants virus is a six-helix bundle assembly. Biochemistry. 2003:42:922-31.

6. Yin HS, Wen X, Paterson RG, Lamb RA, Jardetzky TS. Structure of the parainfluenza virus $5 \mathrm{~F}$ protein in its metastable, prefusion conformation. Nature. 2006;439:38-44. 
7. Heminway BR, Yu Y, Galinski MS. Paramyxovirus mediated cell fusion requires co-expression of both the fusion and hemagglutinin-neuraminidase glycoproteins. Virus Res. 1994;31:1-16.

8. Hu XL, Ray R, Compans RW. Functional interactions between the fusion protein and hemagglutinin-neuraminidase of human parainfluenza viruses. J Virol. 1992;66:1528-34

9. Iorio RM, Melanson VR, Mahon PJ. Glycoprotein interactions in paramyxovirus fusion. Future Virol. 2009;4:335-51.

10. Morrison J, Yang JC, Stewart M, Neuhaus D. Solution NMR study of the interaction between NTF2 and nucleoporin FxFG repeats. J Mol Biol. 2003; 333:587-603.

11. Corey EA, lorio RM. Mutations in the stalk of the measles virus hemagglutinin protein decrease fusion but do not interfere with virus-specific interaction with the homologous fusion protein. J Virol. 2007;81:9900-10.

12. Ennis MK, Hu C, Naik SK, Hallak LK, Peng KW, Russell SJ, Dingli D. Mutations in the stalk region of the measles virus hemagglutinin inhibit syncytium formation but not virus entry. J Virol. 2010;84:10913-7.

13. Gravel KA, McGinnes LW, Reitter J, Morrison TG. The transmembrane domain sequence affects the structure and function of the Newcastle disease virus fusion protein. J Virol. 2011;85:3486-97.

14. Kumar S, Nayak B, Collins PL, Samal SK. Evaluation of the Newcastle disease virus $\mathrm{F}$ and $\mathrm{HN}$ proteins in protective immunity by using a recombinant avian paramyxovirus type 3 vector in chickens. J Virol. 2011;85:6521-34.

15. Lee B, Ataman ZA. Modes of paramyxovirus fusion: a Henipavirus perspective. Trends Microbiol. 2011;19:389-99.

16. Plemper RK, Lakdawala AS, Gernert KM, Snyder JP, Compans RW. Structural features of paramyxovirus $F$ protein required for fusion initiation. Biochemistry. 2003;42:6645-55.

17. Luque LE, Russell CJ. Spring-loaded heptad repeat residues regulate the expression and activation of paramyxovirus fusion protein. J Virol. 2007; 81:3130-41

18. Russell CJ, Kantor KL, Jardetzky TS, Lamb RA. A dual-functiona paramyxovirus $F$ protein regulatory switch segment: activation and membrane fusion. J Cell Biol. 2003;163:363-74.

19. Schowalter RM, Chang A, Robach JG, Buchholz UJ, Dutch RE. Low-pH triggering of human metapneumovirus fusion: essential residues and importance in entry. J Virol. 2009;83:1511-22.

20. Smith EC, Popa A, Chang A, Masante C, Dutch RE. Viral entry mechanisms: the increasing diversity of paramyxovirus entry. FEBS J. 2009;276:7217-27.

21. Wang Z, Bao J, Wu X, Liu Y, Li L, Liu C, Suo L, Xie Z, Zhao W, Zhang $W$, et al. Peste des petits ruminants virus in Tibet, China. Emerg Infect Dis. 2009;15:299-301.

22. Chenail G, Brown NE, Shea A, Feire AL, Deng G. Real-time analysis of antibody interactions with whole enveloped human cytomegalovirus using surface plasmon resonance. Anal Biochem. 2011:411:58-63.

23. Davis TM, Wilson WD. Surface plasmon resonance biosensor analysis of RNA-small molecule interactions. Methods Enzymol. 2001;340:22-51.

24. Kodoyianni V. Label-free analysis of biomolecular interactions using SPR imaging. BioTechniques. 2011:50:32-40.

25. Lofgren JA, Dhandapani S, Pennucci JJ, Abbott CM, Mytych DT, Kaliyaperumal A, Swanson SJ, Mullenix MC. Comparing ELISA and surface plasmon resonance for assessing clinical immunogenicity of panitumumab. J Immunol. 2007;178:7467-72

26. Rich RL, Myszka DG. Higher-throughput, label-free, real-time molecular interaction analysis. Anal Biochem. 2007:361:1-6.

27. Riedel T, Majek P, Rodriguez-Emmenegger C, Brynda E. Surface plasmon resonance: advances of label-free approaches in the analysis of biological samples. Bioanalysis. 2014;6:3325-36.

28. Stubenrauch K, Wessels U, Vogel R, Schleypen J. Evaluation of a biosensor immunoassay for simultaneous characterization of isotype and binding region of human anti-tocilizumab antibodies with control by surrogate standards. Anal Biochem. 2009;390:189-96.

29. Wang S, Poon GM, Wilson WD. Quantitative investigation of protein-nucleic acid interactions by biosensor surface Plasmon resonance. Methods Mol Biol. 2015;1334:313-32

30. Weeraratne DK, Lofgren J, Dinnogen S, Swanson SJ, Zhong ZD. Development of a biosensor-based immunogenicity assay capable of blocking soluble drug target interference. J Immunol Methods. 2013; 396:44-55.

31. Willander M, Al-Hilli S. Analysis of biomolecules using surface plasmons. Methods Mol Biol. 2009:544:201-29.
32. Tiwari PB, Annamalai T, Cheng B, Narula G, Wang X, Tse-Dinh YC, He J, Darici Y. A surface plasmon resonance study of the intermolecular interaction between Escherichia Coli topoisomerase I and pBAD/Thio supercoiled plasmid DNA. Biochem Biophys Res Commun. 2014;445:445-50.

33. Homola J. Surface plasmon resonance sensors for detection of chemical and biological species. Chem Rev. 2008;108:462-93.

34. Papalia GA, Giannetti AM, Arora N, Myszka DG. Thermodynamic characterization of pyrazole and azaindole derivatives binding to p38 mitogen-activated protein kinase using Biacore T100 technology and van't Hoff analysis. Anal Biochem. 2008;383:255-64.

35. Rich RL, Myszka DG. Survey of the 1999 surface plasmon resonance biosensor literature. J Mol Recognit. 2000;13:388-407.

36. Liu C, Cui D, Li H. A hard-soft microfluidic-based biosensor flow cell for SPR imaging application. Biosens Bioelectron. 2010;26:255-61.

37. Mochizuki Y, Suzuki T, Fujimoto K, Nemoto N. A versatile puromycin-linker using cnvK for high-throughput in vitro selection by cDNA display. J Biotechnol. 2015;212:174-80.

38. Morrison TG. Structure and function of a paramyxovirus fusion protein. Biochim Biophys Acta. 2003;1614:73-84.

39. Bose S, Welch BD, Kors CA, Yuan P, Jardetzky TS, Lamb RA. Structure and mutagenesis of the parainfluenza virus 5 hemagglutinin-neuraminidase stalk domain reveals a four-helix bundle and the role of the stalk in fusion promotion. J Virol. 2011;85:12855-66.

40. Ben-Efraim I, Kliger Y, Hermesh C, Shai Y. Membrane-induced step in the activation of Sendai virus fusion protein. J Mol Biol. 1999;285:609-25.

41. Lambert DM, Barney S, Lambert AL, Guthrie K, Medinas R, Davis DE, Bucy T, Erickson J, Merutka G, Petteway SR Jr. Peptides from conserved regions of paramyxovirus fusion (F) proteins are potent inhibitors of viral fusion. Proc Natl Acad Sci U S A. 1996;93:2186-91.

42. Joshi SB, Dutch RE, Lamb RA. A core trimer of the paramyxovirus fusion protein: parallels to influenza virus hemagglutinin and HIV-1 gp41. Virology. 1998;248:20-34

43. Rapaport D, Ovadia M, Shai Y. A synthetic peptide corresponding to a conserved heptad repeat domain is a potent inhibitor of Sendai virus-cell fusion: an emerging similarity with functional domains of other viruses. EMBO J. 1995;14:5524-31.

44. Wild C, Oas T, McDanal C, Bolognesi D, Matthews T. A synthetic peptide inhibitor of human immunodeficiency virus replication: correlation between solution structure and viral inhibition. Proc Natl Acad Sci U S A. 1992;89: 10537-41.

45. Wild TF, Fayolle J, Beauverger P, Buckland R. Measles virus fusion: role of the cysteine-rich region of the fusion glycoprotein. J Virol. 1994;68:7546-8.

46. Yao Q, Compans RW. Peptides corresponding to the heptad repeat sequence of human parainfluenza virus fusion protein are potent inhibitors of virus infection. Virology. 1996;223:103-12.

47. Young JK, Hicks RP, Wright GE, Morrison TG. Analysis of a peptide inhibitor of paramyxovirus (NDV) fusion using biological assays, NMR, and molecular modeling. Virology. 1997:238:291-304.

48. Yuan P, Swanson KA, Leser GP, Paterson RG, Lamb RA, Jardetzky TS. Structure of the Newcastle disease virus hemagglutinin-neuraminidase $(\mathrm{HN})$ ectodomain reveals a four-helix bundle stalk. Proc Natl Acad Sci U S A. 2011;108:14920-5.

49. Lee JK, Prussia A, Snyder JP, Plemper RK. Reversible inhibition of the fusion activity of measles virus $F$ protein by an engineered intersubunit disulfide bridge. J Virol. 2007:81:8821-6.

50. Lee JK, Prussia A, Paal T, White LK, Snyder JP, Plemper RK. Functional interaction between paramyxovirus fusion and attachment proteins. J Biol Chem. 2008;283:16561-72

51. Gravel C, Li C, Wang J, Hashem AM, Jaentschke B, Van Domselaar G, He R, Li X Quantitative analyses of all influenza type A viral hemagglutinins and neuraminidases using universal antibodies in simple slot blot assays. J Vis Exp. 2011,(50). https://doi.org/10.3791/2784.

52. Boozer C, Kim G, Cong S, Guan H, Londergan T. Looking towards labelfree biomolecular interaction analysis in a high-throughput format: a review of new surface plasmon resonance technologies. Curr Opin Biotechnol. 2006:17:400-5. 